\title{
COVID-19: The Influence of ACE Genotype and ACE-I and ARBs on the Course of SARS-CoV-2 Infection in Elderly Patients
}

This article was published in the following Dove Press journal: Clinical Interventions in Aging

\author{
Jerzy Sieńko (D) \\ Maciej Kotowski (D) \\ Anna Bogacz $\mathbb{D}^{2}$ \\ Kacper Lechowicz $\mathbb{1 D}^{3}$ \\ Sylwester Drożdżal ${ }^{4}$ \\ Jakub Rosik (D) ${ }^{5}$ \\ Marek Sietnicki $\mathbb{D}^{6}$ \\ Magdalena Sieńko ${ }^{7}$ \\ Katarzyna Kotfis (D) $^{3}$
}

'Department of General Surgery and Transplantology, Pomeranian Medical University in Szczecin, Szczecin, Poland;

${ }^{2}$ Department of Pharmacology and Phytochemistry, Institute of Natural Fibers and Medicinal Plants, Poznan, Poland; ${ }^{3}$ Department of Anaesthesiology, Intensive Therapy and Acute Intoxications, Pomeranian Medica University in Szczecin, Szczecin, Poland; ${ }^{4}$ Department of Pharmacokinetics and Monitored Therapy, Pomeranian Medical University in Szczecin, Szczecin, Poland; ${ }^{5}$ Department of Physiology, Pomeranian Medical University in Szczecin, Szczecin, Poland; ${ }^{6}$ Department of Civil Engineering and Architecture, West Pomeranian University of Technology in Szczecin, Szczecin, Poland; ' Department of Pediatrics, Endocrinology, Diabetology, Metabolic Diseases and Cardiology, Pomeranian Medical University in Szczecin, Szczecin, Poland

Correspondence: Katarzyna Kotfis Department of Anaesthesiology, Intensive Therapy and Acute Intoxications, Pomeranian Medical University in Szczecin, Al. Powstańców Wielkopolskich 72, Szczecin 70-1II, Poland $\mathrm{Tel} / \mathrm{Fax}+48$ 9l 466 II 44 Email katarzyna.kotfis@pum.edu.pl

\begin{abstract}
Since the beginning of 2020, the whole world has been struggling with the pandemic of Coronavirus Disease 2019 (COVID-19) caused by a novel coronavirus SARS-CoV-2. The SARS-CoV-2 infection depends on ACE2, TMPRSS2, and CD147, which are expressed on host cells. Several studies suggest that some single nucleotide polymorphisms (SNPs) of ACE2 might be a risk factor of COVID-19 infection. Genotypes affect ACE2 structure, its serum concentration, and levels of circulating angiotensin (1-7). Moreover, there is evidence that ACE genotype affects the outcomes of acute respiratory distress syndrome (ARDS) treatment, the most severe consequence of SARS-CoV-2 infection. COVID-19 morbidity, infection course, and mortality might depend on ACE D allele frequency. The aim of this narrative review was to analyze and identify the mechanisms of ACE-I and ARBs with particular emphasis on angiotensin receptors and their polymorphism in the light of COVID-19 pandemic as these medications are commonly prescribed to elderly patients. There is no direct evidence yet for ACE-I or ARBs in the treatment of COVID-19. However, for those already taking these medications, both the European Society of Cardiology and the American College of Cardiology recommend continuing the treatment, because at present, there is no clear clinical or scientific evidence to justify the discontinuation of ACE-I or ARBs. Individualized treatment decisions should be based on the clinical condition and co-morbidities of each patient.
\end{abstract}

Keywords: SARI, hypertension, coronavirus, age, ACEI, ARB

\section{Introduction}

Since the beginning of the year 2020, the whole world has been struggling with the epidemic of the new SARS-CoV-2 virus causing Coronavirus Disease 2019 (COVID-19). It was first detected in the Chinese province of Hubei at the end of 2019, and in March 2020 the World Health Organization (WHO) recognized COVID-19 as a global health threat by declaring it a global pandemic. ${ }^{1}$

SARS-CoV-2 is a novel virus from the Coronaviridae family, mainly found as a pathogen in animals (birds and mammals). ${ }^{1,2}$ History has already seen human infections with other viruses from this family. ${ }^{3,4}$ Both SARS-CoV-1 causing Severe Acute Respiratory Syndrome (SARS) and MERS-CoV causing Middle East Respiratory Syndrome (MERS) show similarity to SARS-CoV-2 causing COVID-19 by using receptors for Angiotensin II (AngII) for viral entry into the cell during infection. These receptors are found throughout the human body, with large numbers occurring in the lungs, especially on type 2 pneumocytes, which explains why the symptoms are mainly associated with the respiratory system. ${ }^{3,4}$ 
The main source of infection spread is droplet and direct contact, but fecal-oral route and direct intraneural entry through olfactory nerves have been suggested. ${ }^{5-7}$ Usually, the SARS-CoV-2 infection is asymptomatic, while symptoms include fever, weakness, myalgia, cough, difficulty breathing, sometimes abdominal discomfort and diarrhea or anosmia. ${ }^{6-8}$ It has also been suggested that neurological presentation, including delirium, may precede respiratory symptoms. ${ }^{9,10}$ It is important to identify laboratory abnormalities associated with COVID-19, including leuko- and lymphopenia, thrombocytopenia, elevated lactate dehydrogenase level, increased liver enzymes or d-dimers. ${ }^{11,12}$ People with symptoms often develop rapidly progressing infections of the lower respiratory tract, which can lead to viral pneumonia and Severe Acute Respiratory Infection (SARI), as well as sepsis and death. ${ }^{8,13}$

The aim of this narrative review was to analyze and identify the mechanisms of ACE-I and ARBs with particular emphasis on angiotensin receptors and their polymorphism in the light of COVID-19 pandemic as these medications are commonly prescribed to elderly patients. The selected literature review is based on an in-depth analysis and selection of articles in terms of their credibility and relevance to the topic. This is only a small part of the available literature on the topic, but we chose the most reliable individual articles for the purpose of this review.

\section{Connection Between RAS Activity, Age and COVID-I 9 Epidemiology}

In estimating the course of the disease, the most common patient profile is important. The current meta-analyzes determine the average age of the patient to be between 30 and 79 years of age. ${ }^{13}$

Concomitant diseases and multimorbidity are serious problems of modern times. One of the main civilization diseases is hypertension. ${ }^{14}$ The possibility of a coexistence of hypertension and susceptibility for SARS-CoV-2 infection raises many questions; therefore, it is important to know the pathogenesis and mechanisms of both diseases. We chose several, most recent articles describing these mechanisms.

Changes in RAS activity are related to the pathogenesis of hypertension and inflammatory lung disease. Targeting RAS is an effective antihypertension therapeutic strategy. ACEIs and ARB, which inhibit the ACE/Ang II/AT1R system, are commonly used drugs for hypertensive patients. ${ }^{13}$ In a study on a rat model in 12-day treatment with drugs that either inhibit the synthesis of circulating Ang II or block the AT1 receptor, the therapy induced an increase in ACE2 heart mRNA, accompanied by an increase in ACE2 activity in the heart membrane of rats treated with any of losartan or both losartan and lisinopril. Although the dominant effect of ACE inhibition may be due to the combined effect of reduced Ang II formation and Ang 1-7 metabolism (1-7), the antihypertensive effect of AT1 antagonists may be partially due to increased Ang II metabolism by ACE2 ${ }^{15}$ The current study confirmed that increased age was associated with death in patients with COVID-19. Previous studies in macaques inoculated with SARS-CoV found that older macaques had stronger host innate responses to virus infection than younger adults, with an increase in differential expression of genes associated with inflammation, whereas expression of type I interferon beta was reduced. The age-dependent defects in T-cell and B-cell function and the excess production of type 2 cytokines could lead to a deficiency in the control of viral replication and more prolonged proinflammatory responses, potentially leading to poor outcome. ${ }^{16}$ More than half of these people suffer from associated diseases, mainly hypertension - the most common chronic disease in the elderly. ${ }^{17-19}$ The most commonly used drug groups in antihypertensive therapy are angiotensinconverting enzyme inhibitors (ACE-I) and angiotensin receptor blockers (ARBs). ${ }^{20}$ Due to the mechanism of development of COVID-19 infection, questions arise about the legitimacy of the use of these drugs in the treatment of patients and the risks or therapeutic options associated with it should be identified.

\section{The Role of Renin-Angiotensin System in COVID-I 9 Infection}

It has been proven that SARS-CoV-2 infection depends on ACE2 interaction with the virus (Figure 1). This indicates that the role of the renin-angiotensin (RA) system in the physiology and pathophysiology of the cardiovascular system is of major importance. In the lungs, angiotensin I (ANG I) is being converted to angiotensin II (ANG II). Further, ANG II binds to either AT1 receptor (AT1R) causing vasoconstriction, hypertension, promoting inflammation, and may be converted to angiotensin (ANG IV) via AT4 receptor (AT4R) causing thrombosis. The role of ACE2 is to inactivate ANG II by converting it to angiotensin (1-7) (ANG $(1-7))$ that binds to Mas receptor causing vasodilation and hypotension. Thus, in a healthy individual, ACE2 negatively 


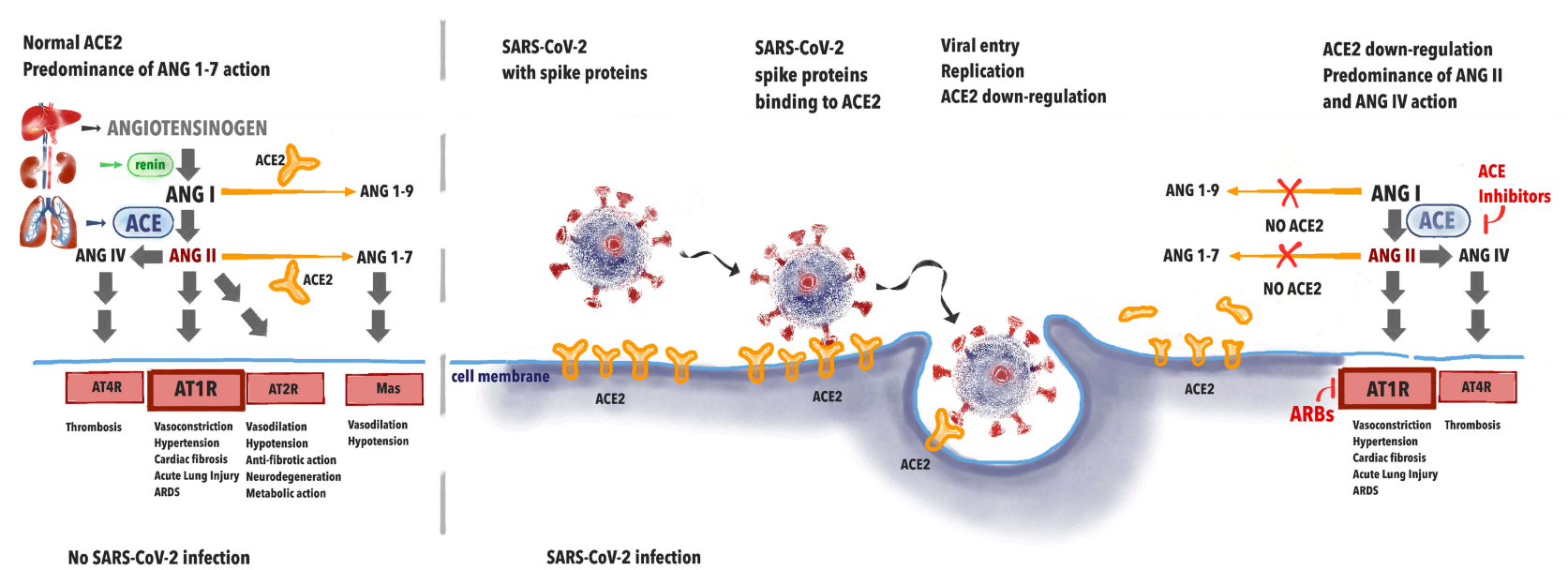

Figure I The effects of renin-angiotensin system during SARS-CoV-2 infection.

regulates the renin-angiotensin (RA) system and attenuates vasoconstriction, fibrosis, and hypertrophy induced by it. ${ }^{21}$

When the spike protein of SARS-CoV-2 binds with ACE2 this leads to the internalization of the complex and further to ACE2 shedding by enzyme ADAM17. In 2005 , studies appeared on the effect of Tumor Necrosis Factor- $\alpha$ Convertase (ADAM17) on the penetration of SARS virus into the cells. ADAM17 overexpression has been shown to lead to increased virus penetration. ${ }^{22}$ Palau et al analyzed data on this metalloproteinase in the context of COVID-19 infection. ${ }^{23}$ ADAM17 has been shown to compete with TMPRSS2 for ACE2, which, in light of the reports regarding the effect of TMPRSS2 on viral penetration, forces further research into the mechanisms of viral penetration to prevent infection. ${ }^{23,24}$

Decreased availability of ACE2 causes less ANG II degradation. Excessive amounts of ANG II lead not only to overstimulation of AT1R but to conversion to ANG IV which promotes thrombosis via AT4R. This leads to abnormalities seen in COVID-19, namely acute lung injury with local vasoconstriction facilitating ARDS, myocardial injury, and thrombosis. ${ }^{25}$ The potential effect of ACE-I/ARBs treatment may be seen in upregulation of ACE2, leading to the increased amounts of free ACE2 after viral binding. ACE-Inhibitors (ACE-I) cause less synthesis of ANG II and ARBs prevent ANGII from binding on the AT1R. This leads to less AT1R stimulation and persistent interaction with ACE2, avoiding ACE2 internalization. ACE-2 is available for the transformation of ANGI I into Angiotensin (1-7), causing less AT1R and AT4R stimulation.

\section{ACE2 Expression and ACE2 Gene Polymorphisms}

SARS-CoV-2 infection depends not only on ACE2, but also on TMPRSS2, a cellular protease and CD147 (extracellular matrix metalloproteinase inducer - EMMPRIN) which are expressed on host cells. ${ }^{24,26-28}$ ACE2, the homolog of ACE, is composed of a single zinc metalloprotease active site, identical to ACE only in $42 \%$, and a transmembrane domain. ${ }^{29-31}$ Its expression is not so unique in organs as ACE. ACE2 transcripts are found in the renal tubular epithelium, testis, type 2 pneumocytes, endothelium of coronary and intrarenal vessels. ${ }^{29,32,33}$ ACE2 is present in serum after cleavage of the transmembrane domain. ${ }^{29}$ This soluble form might limit CoVs infection ${ }^{34,35}$ and if combined with $\mathrm{Fc}$ fragment of the antibody, it neutralizes the virus. ${ }^{36}$ The aforementioned findings suggest that the course of infection might depend on the ACE2 expression.

ACE2 activity is negatively correlated with blood pressure and BMI. ${ }^{37}$ It is hypothesized that ACE2 activity is a predictor of cardiac dysfunction in patients with hypertension. ${ }^{37}$ However, Chen et al found that circulating ACE2 levels are positively associated with serum creatinine, a marker of kidney disease. ${ }^{38}$

ACE2 is located on a short arm of a chromosome $\mathrm{X}$ (Xp22.2) and comprises 19 exons. ${ }^{29,39}$ Since its identification as a potentially functional for cardiovascular diseases, there have been many trials verifying the hypothetical influence of Single Nucleotide Polymorphisms (SNPs) located within ACE2 gene. ${ }^{39}$ ACE2 might influence cardiovascular diseases even before birth. A study on 474 samples of umbilical cord blood connected rs2074192 (T allele) with 
a probability of being born as small for gestational age $(\mathrm{SGA})-\mathrm{OR}=22.93(\mathrm{p}<0.05) . \mathrm{SGA}$ is associated with cardiovascular diseases in adulthood. ${ }^{40}$

Many ACE2 variants are related to common diseases, whose incidence depends on the balance in the reninangiotensin-aldosterone pathway, as depicted in Table 1. Hypertension is associated with rs1514283, rs2074192, rs233575, rs4646155, rs4646176, rs2285666, rs879922, rs2106809, rs4646188, rs4240157, rs4830542, rs2158083, and $\mathrm{rs} 879922 . .^{37,41,42}$ Some of these variants affect the response to ACE inhibitors. ${ }^{43,44}$ Moreover, rs2285666 (A allele) is associated with lower probability of cardiovascular death in female population $(\mathrm{HR}=0.3, \mathrm{p}<0.05) .{ }^{41,45,46}$ Amongst people with hypertension minor alleles: rs2106809 and rs2074192 are associated with left ventricular hypertrophy. ${ }^{47}$ Lieb et al found the association between rs4646156, rs879922, rs4240157, rs233575 and higher septal wall thickness or left ventricular hypertrophy in male population. ${ }^{48}$ This association might be a result of lower levels of circulating Angiotensin (1-7) in this group. ${ }^{38}$ Wang et al conducted a study on 265 with atrial fibrillation (AF) and 289 healthy people. Researchers found that rs2106809 (T allele) is AF risk factor. ${ }^{49}$

ACE2 SNPs might influence patients' lipid profiles. LDL concentration is associated with rs1978124, rs2106809, rs233575, rs4646188, and rs879922. HDL concentration might be decreased in individuals with rs2106809, rs2285666, rs4646142, rs4646155, and rs4646188. ${ }^{41}$ SNPs: rs2106809 and rs4646188 are risk factors for hypertriglyceridemia. ${ }^{41}$

Table I The Most Important ACE2 SNPs Related to Essential Hypertension

\begin{tabular}{|l|l|}
\hline Disease & ACE2 Single Nucleotide Polymorphisms \\
\hline $\begin{array}{l}\text { Essential } \\
\text { hypertension }\end{array}$ & $\begin{array}{l}\text { rs1514283, rs2074192, rs233575, rs4646155, } \\
\text { rs4646176, rs2285666, rs879922, rs2106809, } \\
\text { rs879922 }\end{array}$ \\
\hline $\begin{array}{l}\text { Cardiovascular } \\
\text { death }\end{array}$ & rs2285666 \\
\hline $\begin{array}{l}\text { Left ventricular } \\
\text { hypertrophy }\end{array}$ & $\begin{array}{l}\text { rs2106809, rs2074192, rs4646I56, rs879922, } \\
\text { rs4240157, rs233575 }\end{array}$ \\
\hline Atrial fibrillation & rs2106809 \\
\hline Dyslipidemia & $\begin{array}{l}\text { rs1978I24, rs2106809, rs233575, rs4646188, } \\
\text { rs879922, rs2285666, rs4646142, rs4646I55 }\end{array}$ \\
\hline
\end{tabular}

Abbreviation: ACE2, angiotensin-converting eEnzyme 2.
Some projects failed to find any association between ACE2 variants and diseases, whose frequency is correlated with blood pressure. Wu et al did not find any association between SNPs and recurrent strokes. ${ }^{50}$

The aforementioned results suggest that some SNPs might be a risk factor of COVID-19. Genotypes affect ACE2 structure, its serum concentration, and levels of circulating angiotensin (1-7). ${ }^{38,51}$ Moreover, there is evidence that ACE genotype affects the outcomes of acute respiratory distress syndrome (ARDS) treatment. In a prospective study on 84 patients with ARDS and 200 healthy people, ACE polymorphisms were genotyped. Every study participant was Caucasian. Researchers found that being homozygous for ACE D (deletion in intron 16) allele was associated with increased mortality. ${ }^{52}$ Geographic distribution of ACE I (insertion in intron 16) allele was summarized by Saab et al Its frequency increases eastwards and westwards from the Middle East. ${ }^{53}$ It was proven that ACE2 decrease the risk of lung failure. ${ }^{33}$ Nevertheless, Chiu et al did not find any significant association between ACE2 variants and SARS. ${ }^{54}$ Another interesting study by Goulter et al proved the connection between heart failure and ACE2 expression. ACE2 is probably upregulated due to idiopathic dilated cardiomyopathy and ischemic cardiomyopathy. ${ }^{55}$ It needs to be verified if these diseases affect the likelihood of COVID-19.

COVID-19 morbidity, infection course, and mortality might depend on ACE D allele frequency. ${ }^{56}$ Delanghe et al's findings are unanimous with the role of ACE in CoVs infections. ${ }^{57}$ Stawiski et al performed genomic datasets analysis and identified multiple ACE2 variants, which might affect COVID-19 susceptibility. ${ }^{58}$ However, none of these SNPs is common in the general population. This finding might help in the recognition of people less and more prone to COVID-19. ${ }^{58}$ Cao et al performed a genetic dataset analysis of various populations for polymorphisms in the ACE2 structure. The differences between populations and higher tissue expression of ACE2 in East Asian populations were determined, which may suggest other susceptibility to infection. However, the studies did not show genetic evidence confirming the existence of the ACE2 mutation resistant to coronavirus protein. ${ }^{59}$

\section{Treatment with ACE-I and ARBs During COVID-I 9 Pandemic}

Co-morbid conditions, including hypertension, diabetes, heart disease, and progressive age have been found to contribute to more severe disease in patients with 
COVID-19. In addition, these patients were more often admitted to the intensive care unit, received mechanical ventilation, or died compared to patients with mild disease. ${ }^{60}$ Due to the fact that in these diseases, groups of drugs that are often used are drugs that have an inhibitory effect on the RAAS system, there are concerns that they may have contributed to some degree of adverse health effects or more severe course of this disease. ${ }^{16,60}$

ACE2 is a key enzyme that breaks down Angiotensin II into Angiotensin (1-7), thus reducing its effect on vasoconstriction, sodium retention, water retention, and fibrosis. Although Angiotensin II is the basic substrate for ACE2, this enzyme also degrades Angiotensin I to Angiotensin (1-9) and is involved in the hydrolysis of other peptides. ${ }^{61}$ The balance of these vasoactive peptides has a profound effect on organs and systems and is altered by both ACE inhibitors (which block the action of ACE-1) and ARBs (which block the action of angiotensin II on AT1 receptors). Studies of human tissue samples from 15 different organs have been shown to generally express ACE2, including in the heart and kidneys, as well as in major SARS-CoV-2 target cells (and the site of the dominant injury) - follicular epithelial cells. ${ }^{32}$ In addition, circulating soluble ACE2 levels are relatively low, and the functional role of ACE2 in the lungs appears to be relatively minimal under normal conditions but might be elevated in some specific clinical conditions. ${ }^{62}$

There are many hypotheses about the pathomechanism and impact of using ACE-I and ARBs. One of them says that ACEI initially inhibits ACE, which leads to a decrease in the level of angiotensin I, resulting in a possible negative feedback loop, which ultimately regulates more of the ACE2 receptor to be able to interact with the available substrate of Angiotensin I. ${ }^{63}$ This upregulation of the ACE2 receptor causes an increase in SARS-CoV-2 binding sites, which can lead to COVID-19 infection. This can be especially seen in patients with diabetes or hypertension, as they are usually treated with ACE-I or ARB. ${ }^{63}$ An April 2020 a study including patients hospitalized in the Hubei Province in China found a death rate of 3.7\% for hospitalized patients who had hypertension and were on ACE-I or ARBs versus 9.8\% for hospitalized patients with hypertension not on such drugs, suggesting that the drugs are not harmful and may help against the coronavirus. ${ }^{64}$

Otherwise, some researchers believe that using ACE-I or ARBs may be beneficial in preventing COVID-19 infection. Li et al proposed that ACE1 inhibition by ACE-I may stimulate negative feedback. Given the lack of Angiotensin II, an increase in ACE2 receptors and a reduction in general inflammation. ${ }^{65}$

Probably the effect on the renin-angiotensin system by both ACE-I and ARBs leads to increased expression of ACE2. Theoretically, this may help alleviate some of the harmful effects of Angiotensin II on the human body. It is believed that the increased level of soluble ACE2 may act as competitive to SARS-CoV-2 and may slow down the penetration of the virus into cells and protect against damage to lung tissue. ${ }^{30}$ There is some evidence that ACE-I/ARBs may be beneficial in patients with acute lung injury (ALI) or ARDS as a complication after COVID-19 infection. In a meta-analysis of 37 studies, the use of ACE-I and ARBs was associated with a reduced risk of pneumonia and mortality from pneumonia compared to control treatment. ${ }^{66}$

In one randomized, double-blind, placebo-controlled clinical trial in 61 patients, 8 patients randomly received enalapril up to $10 \mathrm{mg}$ intravenously (within 24 hours after a blood pressure regimen) had more days without assisted ventilation (12.3 vs. 8.7 days; $\mathrm{P}=0.18$ ) and days spent outside of the intensive care unit ( 8.9 vs. 4.9 days; $\mathrm{P}=$ $0.09)$ compared to those randomly assigned to placebo. This study has not yet been completed due to the slow registration of patients. ${ }^{67}$

In another Korean retrospective study of 132 patients with ARDS, 9 patients receiving ACE-I/ARBs showed better survival compared to the control group, although other determinants could influence the results. ${ }^{68}$

Sun et al proposed that ACE-I use implies the ACE receptor/Angiotensin II/Angiotensin-1 receptor pathway and thus interferes with the integrity of ACE2/Angiotensin 1-7/Mas (MAS-associated G-protein coupled receptor). ACE2/angiotensin disruption Route 1-7/Mas may lead to a decrease in ACE2 production, reducing the chance of SARS-CoV-2 getting into the cell. ${ }^{69}$

One study to date has looked at the effects of ACE-I and ARB on the COVID-19 population. According to Peng et al among 112 patients, cardiovascular disease led to worse outcomes, with most deaths following fulminant inflammation, lactic acidosis and thrombotic conditions. The use of ACE-I and ARB did not affect morbidity or mortality. $^{70}$

Receptor polymorphisms have been inclining towards genetic research and phenotyping for years. The main reason for consideration is the lack of response to the treatment of hypertension by ACE-I and ARBs. In 2007, Danser et al proposed ACE phenotyping to explain 
differences in response to ace inhibitors. ${ }^{71}$ Since then, there have been studies in which researchers have focused on convertase variants, while there has been little interest in the receptors themselves. Because of the much more important role played by receptors in infection, Sommerstein et al analyzed the impact of ACE-I and ARBs on COVID-19. ${ }^{69}$ Due to many variables such as age, gender and comorbidities, they were unable to determine the effect of these drugs on the development of infection, but they proved that patients using ACE-I had an increase in the number of ACE2 receptors. Therefore, more research is needed because of the popularity of these drugs. $^{72}$ Zhixin Liu et al conducted a large genetic analysis comparing the structure of the virus and receptors in many animals to detect potential carriers of the virus. Animals possessing an ACE receptor with human-like properties may constitute a reservoir other than bats. ${ }^{73}$

Thanks to such research, we are able to determine where the virus can exist as a potential source of another infection despite the removal of an infectious focus in humans. This type of research, based on the analysis of receptor structure, may be the key to predicting the severity of patient infections, detecting particularly sensitive patients, and maybe even discovering a treatment by preventing the virus from entering the cells.

Table 2 Interventional Clinical Trials Verifying the Influence of RAS Blocking on Course and Outcomes of COVID-19

\begin{tabular}{|c|c|c|c|}
\hline $\begin{array}{l}\text { Clinical Trial } \\
\text { ID }\end{array}$ & $\begin{array}{l}\text { Number of } \\
\text { Participants }\end{array}$ & Intervention in Experimental Groups & $\begin{array}{l}\text { Estimated Study } \\
\text { Completion Date }\end{array}$ \\
\hline NCT0434300I & 10,000 & Aspirin vs Losartan vs Simvastatin & $2021-08$ \\
\hline NCT043280I2 & 4000 & Losartan vs Lopinavir/Ritonavir vs Hydroxychloroquine & $2021-04-01$ \\
\hline NCT04330300 & 2414 & Replacing ACE-I and ARB & $2021-03-01$ \\
\hline NCT04359953 & 1600 & Hydroxychloroquine vs Azithromycin vs Telmisartan & $2021-06-01$ \\
\hline NCT04356495 & 1057 & Hydroxychloroquine vs Imatinib vs Favipiravir vs Telmisartan & $2020-08-15$ \\
\hline NCT04335786 & 651 & Valsartan & $2021-12$ \\
\hline NCT04394II7 & 605 & ARB & $2021-04-30$ \\
\hline NCT043III77 & 580 & Losartan & $2021-04-01$ \\
\hline NCT04366050 & 560 & Ramipril & $2021-04$ \\
\hline NCT04329195 & 554 & Discontinuation of RAS blocker therapy & 2020-08-09 \\
\hline NCT04364893 & 500 & Suspension of ACE-I and ARB & $2020-|2-0|$ \\
\hline NCT0435I724 & 500 & $\begin{array}{l}\text { Chloroquine/Hydroxychloroquine vs Lopinavir/Ritonavir vs Rivaroxaban vs } \\
\text { Thromboprophylaxis vs Candesartan vs non-RAS blocking antihypertensives vs } \\
\text { Clazakizumab }\end{array}$ & $2020-|2-3|$ \\
\hline NCT043494IO & 500 & $\begin{array}{l}\text { Hydroxychloroquine }+ \text { Azithromycin vs Hydroxychloroquine }+ \text { Doxycycline vs } \\
\text { Hydroxychloroquine }+ \text { Clindamycin vs Hydroxychloroquine }+ \text { Clindamycin }+ \\
\text { Primaquine vs Remdesivir vs Tocilizumab vs Methylprednisolone vs Interferon- } \\
\text { Alpha2B vs Losartan vs Convalescent Serum }\end{array}$ & || \\
\hline NCT04355936 & 400 & Telmisartan & $2020-|0-0|$ \\
\hline NCT04355429 & 230 & Captopril & $2020-08$ \\
\hline NCT0435I58I & 215 & Discontinuation of ACE-I and ARB & $2020-12$ \\
\hline NCT04353596 & 208 & Stopping/replacing ACE-I and ARB & $2022-05-15$ \\
\hline NCT043I 2009 & 200 & Losartan & $2021-04-01$ \\
\hline NCT04340557 & 200 & Losartan & $2020-|2-3|$ \\
\hline NCT04338009 & 152 & Discontinuation of ACE-I and ARB & $2020-|2-3|$ \\
\hline NCT04345406 & 60 & Captopril or Enalapril & $2029-|2-0|$ \\
\hline NCT04379310 & 54 & ACE-I vs Calcium Channel Blocker & 2020-05-08 \\
\hline NCT04335I 23 & 50 & Losartan & $2020-10$ \\
\hline NCT0436055I & 40 & Telmisartan & $2021-06-30$ \\
\hline NCT04357535 & 17 & ARB or ACE-I & $2020-05-03$ \\
\hline NCT04364984 & 10 & ARB, ACE-I or DRi & $202 I-08-01$ \\
\hline
\end{tabular}

Abbreviations: ACE-I, angiotensin-converting enzyme inhibitors; ARB, angiotensin receptor blocker; DRi, direct renin inhibitors; RAS, renin-angiotensin-aldosterone system. 


\section{Population Studies on the Effect of ACE Inhibitors and ARBs in COVID-I 9}

Constant uncertainty, guesswork, and lack of knowledge about the harmfulness of ACE inhibitors and ARBs in patients with COVID-19 contributed to the creation of population analyzes in this group of patients.

Mancia et al conducted a field study on a group of 6272 infected patients, comparing them with 30,759 controls with similar age, gender, and comorbidities. The results showed that patients with the SARS-CoV-2 virus were more likely to take these drugs; however, this was due to worse health and cardiovascular disease. ACE-I and ARBs have not been shown to affect the risk of COVID19 infection. $^{74}$

Mehra et al analyzed patients from 169 European, Asian, and North American hospitals for mortality and risk factors. The analysis showed that an increased mortality can be observed in patients with chronic obstructive pulmonary disease $(\mathrm{OR}=2.96)$, coronary artery disease $(\mathrm{OR}=2.7)$, heart failure $(\mathrm{OR}=2.48)$, arrhythmia $(\mathrm{OR}=1,95)$, age $>65 \quad(\mathrm{OR}=1.93)$, and smokers $(\mathrm{OR}=1.79)$. There was no statistical significance in increasing the risk of hospital mortality associated with the use of ACE inhibitors $(\mathrm{OR}=0.33)$ and ARBs $(\mathrm{OR}=1.23){ }^{75}$

Reynolds et al also assessed the increased risk of drug use. In patients subjected to COVID-19 diagnostics, the relationship between the use of different classes of hypertensive drugs and the occurrence and severity of the disease itself was evaluated. Again, no statistical significance was demonstrated between the use of any group of drugs for hypertension and the onset of the disease and its severity. ${ }^{76}$

There is no direct evidence yet for ACE or ARB inhibitors in the treatment of COVID-19. However, for those patients already taking these medications, the European Society of Cardiology recommends

That doctors and patients continue treatment because there is no clinical or scientific evidence to suggest that ACE-I or ARBs should be discontinued due to COVID-19 infection. ${ }^{77}$

The American College of Cardiology recommends continuing treatment in conditions such as heart failure, hypertension or ischemic heart disease, and that if COVID-19 occurs, "individualized treatment decisions should be made based on the hemodynamic condition and clinical presentation of each patient" ${ }^{78}$
According to ClinicalTrials.gov webpage, there are currently 26 clinical trials regarding drugs targeting RAS in COVID-19 (summarized in Table 2), e.g.: NCT04312009, NCT04335786, which aim to verify the effects of initiation of the treatment with drugs interfering with RAS in patients with COVID-19 and NCT04338009, NCT04364893, which verify outcomes of discontinuation of ACE-I/ARBs therapy. ${ }^{79}$ NCT04359953 aims to include 1600 participants and the results are expected in December 2020. This trial is designed to compare one of the ARBs - telmisartan with Hydroxychloroquine and Azithromycin in COVID-19 treatment. ${ }^{80}$

\section{Summary}

The SARS-CoV-2 infection depends on ACE2 which is expressed on host cells. There is no direct evidence for the role of ACE-I or ARBs in the treatment of patients with COVID-19. However, for those patients who are already taking these medications, both the European Society of Cardiology and the American College of Cardiology recommend continuing the treatment. Currently, there is no clear clinical or scientific evidence to justify the discontinuation of ACE-I or ARBs. Individualized treatment decisions should be based on age, clinical condition, and co-morbidities of each patient, weighing the benefits of effective treatment of hypertension or heart failure against the risk of abrupt drug discontinuation. Further multicenter prospective studies are necessary to aid clinicians in the decision-making process.

\section{Disclosure}

The authors report no conflicts of interest in this work.

\section{References}

1. Cui J, Li F, Shi Z-L. Origin and evolution of pathogenic coronaviruses. Nat Rev Microbiol. 2019;17(3):181-192. doi:10.1038/s41579-0180118-9

2. Wang L, Zhang Y. Animal coronaviruses: a brief introduction. In: Wang L. (eds) Animal Coronaviruses. Springer Protocols Handbooks. Humana Press, New York, NY. doi:10.1007/978-1-4939-3414-0 1

3. Hui DSC, Zumla A. Severe acute respiratory syndrome: historical, epidemiologic, and clinical features. Infect Dis Clin North Am. 2019;33(4):869-889. doi:10.1016/j.idc.2019.07.001

4. Nassar MS, Bakhrebah MA, Meo SA, Alsuabeyl MS, Zaher WA. Middle East Respiratory Syndrome Coronavirus (MERS-CoV) infection: epidemiology, pathogenesis and clinical characteristics. Eur Rev Med Pharmacol Sci. 2018;22(15):4956-4961. doi:10.26355/ eurrev_201808_15635

5. Yu P, Zhu J, Zhang Z, Han Y. A familial cluster of infection associated with the 2019 novel coronavirus indicating possible person-to-person transmission during the incubation period. $J$ Infect Dis. 2020;221 (11):1757-1761. doi:10.1093/infdis/jiaa077 
6. Kotfis K, Skonieczna-Zydecka K. COVID-19: gastrointestinal symptoms and potential sources of 2019-nCoV transmission. Anaesthesiol Intensive Ther. 2020. doi:10.5114/ait.2020.93867

7. Gu J, Han B, Wang J. COVID-19: gastrointestinal manifestations and potential fecal-oral transmission. Gastroenterology. 2020;158 (6):1518-1519. doi:10.1053/j.gastro.2020.02.054

8. WHO. Clinical management of severe acute respiratory infection when novel coronavirus ( $\mathrm{nCoV}$ ) infection is suspected. Interim guidance. 2020. Available from: https://www.who.int/publications-detail/clini cal-management-of-severe-acute-respiratory-infection-when-novelcoronavirus-(ncov)-infection-is-suspected. Accessed March 13, 2020.

9. Kotfis K, Williams Roberson S, Wilson J, Pun BT, Ely EW. COVID19: what do we need to know about ICU delirium during the SARS-CoV-2 pandemic? Anaesthesiol Intensive Ther. 2020;52 (2):132-138. doi:10.5114/ait.2020.95164

10. Kotfis K, Williams Roberson S, Wilson JE, Dabrowski W, Pun BT, Ely EW. COVID-19: ICU delirium management during SARS-CoV-2 pandemic. Crit Care. 2020;24(1):176. doi:10.1186/s13054-02002882-x

11. Wang D, Hu B, Hu C, et al. Clinical characteristics of 138 hospitalized patients with 2019 novel coronavirus-infected pneumonia in Wuhan, China. JAMA. 2020;323(11):1061. doi:10.1001/jama.2020.1585

12. Kukla M, Skonieczna-Żydecka K, Kotfis K, et al. COVID-19, MERS and SARS with concomitant liver injury-systematic review of the existing literature. J Clin Med. 2020;9(5):5 doi:10.3390/jcm9051420

13. $\mathrm{Wu} \mathrm{Z,} \mathrm{McGoogan} \mathrm{JM.} \mathrm{Characteristics} \mathrm{of} \mathrm{and} \mathrm{important} \mathrm{lessons} \mathrm{from}$ the Coronavirus Disease 2019 (COVID-19) outbreak in China: summary of a report of 72314 cases from the Chinese center for disease control and prevention. JAMA. 2020;323(13):1239. doi:10.1001/ jama.2020.2648

14. Conthe P, Márquez Contreras E, Aliaga Pérez A, et al. Treatment compliance in chronic illness: current situation and future perspectives. Rev Clin Esp. 2014;214(6):336-344. doi:10.1016/j.rce.2014.03.008

15. Ferrario CM, Jessup J, Chappell MC, et al. Effect of angiotensin-converting enzyme inhibition and angiotensin II receptor blockers on cardiac angiotensin-converting enzyme 2. Circulation. 2005;111(20):2605-2610. doi:10.1161/CIRCULATIONAHA.104.510 461

16. Zhou F, Yu T, Du R, et al. Clinical course and risk factors for mortality of adult inpatients with COVID-19 in Wuhan, China: a retrospective cohort study. Lancet. 2020;395(10229):1054-1062. doi:10.1016/S0140-6736(20)30566-3

17. Hassan SA, Sheikh FN, Jamal S, Ezeh JK, Akhtar A. Coronavirus (COVID-19): a review of clinical features, diagnosis, and treatment. Cureus. 2020;12(3):e7355. doi:10.7759/cureus.7355

18. Xu G, Yang Y, Du Y, et al. Clinical pathway for early diagnosis of COVID-19: updates from experience to evidence-based practice. Clin Rev Allergy Immunol. 2020. doi:10.1007/s12016-020-08792-8

19. Mills KT, Stefanescu A, He J. The global epidemiology of hypertension. Nat Rev Nephrol. 2020;16(4):223-237. doi:10.1038/ s41581-019-0244-2

20. Williams B, Mancia G, Spiering W, et al. 2018 practice guidelines for the management of arterial hypertension of the European Society of Hypertension and the European Society of Cardiology: ESH/ESC task force for the management of arterial hypertension. $J$ Hypertens. 2018;36(12):2284-2309. doi:10.1097/HJH.00000000 00001961

21. Hamming I, Cooper ME, Haagmans BL, et al. The emerging role of ACE2 in physiology and disease. J Pathol. 2007;212(1):1-11. doi:10.1002/path.2162

22. Lambert DW, Yarski M, Warner FJ, et al. Tumor necrosis factor-alpha convertase (ADAM17) mediates regulated ectodomain shedding of the severe-acute respiratory syndrome-coronavirus (SARS-CoV) receptor, angiotensin-converting enzyme-2 (ACE2). J Biol Chem. 2005;280(34):30113-30119. doi:10.1074/jbc.M5051 11200
23. Palau V, Riera M, Soler MJ. ADAM17 inhibition may exert a protective effect on COVID-19. Nephrol Dial Transplant. 2020;35 (6):1071-1072. doi:10.1093/ndt/gfaa093

24. Hoffmann M, Kleine-Weber H, Schroeder S, et al. SARS-CoV-2 cell entry depends on ACE2 and TMPRSS2 and is blocked by a clinically proven protease inhibitor. Cell. 2020;181(2):271-280.e8. doi:10.10 16/j.cell.2020.02.052

25. Zores F, Rebeaud ME. COVID and the renin-angiotensin system: are hypertension or its treatments deleterious? Front Cardiovasc Med. 2020;7:71.

26. Zhang H, Penninger JM, Li Y, Zhong N, Slutsky AS. Angiotensinconverting enzyme 2 (ACE2) as a SARS-CoV-2 receptor: molecular mechanisms and potential therapeutic target. Intensive Care Med. 2020;46(4):586-590. doi:10.1007/s00134-020-05985-9

27. Hoffmann M, Kleine-Weber H, Krüger N, Mueller MA, Drosten C, Pöhlmann S. The novel coronavirus 2019 (2019-nCoV) uses the SARS-coronavirus receptor ACE2 and the cellular protease TMPRSS2 for entry into target cells. BioRxiv. 2020.

28. Wang K, Chen W, Zhou Y-S, et al. SARS-CoV-2 invades host cells via a novel route: CD147-spike protein. bioRxiv. 2020;2020.03.14.988345. doi:10.1101/2020.03.14.988345

29. Donoghue M, Hsieh F, Baronas E, et al. A novel angiotensin-converting enzyme-related carboxypeptidase (ACE2) converts angiotensin I to angiotensin 1-9. Circ Res. 2000;87(5):E19. doi:10.1161/01.res.87.5.e1

30. Batlle D, Wysocki J, Satchell K. Soluble angiotensin-converting enzyme 2: a potential approach for coronavirus infection therapy? Clin Sci (Lond). 2020;134(5):543-545. doi:10.1042/CS20200163

31. Turner AJ. ACE2 Cell Biology, Regulation, and Physiological Functions. The Protective Arm of the Renin Angiotensin System (RAS). 2015;185-189. doi:10.1016/B978-0-12-801364-9.00025-0

32. Hamming I, Timens W, Bulthuis MLC, Lely AT, Navis GJ, van Goor H. Tissue distribution of ACE2 protein, the functional receptor for SARS coronavirus. A first step in understanding SARS pathogenesis. J Pathol. 2004;203(2):631-637. doi:10.1002/path.1570

33. Magrone T, Magrone M, Jirillo E. Focus on receptors for coronaviruses with special reference to angiotensin-converting enzyme 2 as a potential drug target - a perspective. Endocr Metab Immune Disord Drug Targets. 2020;20. doi:10.2174/1871530320666200427112902

34. Li W, Moore MJ, Vasilieva N, et al. Angiotensin-converting enzyme 2 is a functional receptor for the SARS coronavirus. Nature. 2003;426(6965):450-454. doi:10.1038/nature02145

35. Ksiazek TG, Erdman D, Goldsmith CS, et al. A novel coronavirus associated with severe acute respiratory syndrome. $N$ Engl J Med. 2003;348(20):1953-1966. doi:10.1056/NEJMoa030781

36. Lei C, Fu W, Qian K, et al. Potent neutralization of 2019 novel coronavirus by recombinant ACE2-Ig. bioRxiv. 2020. doi:10.1101/ 2020.02.01.929976

37. Zhang Q, Cong M, Wang N, et al. Association of angiotensin-converting enzyme 2 gene polymorphism and enzymatic activity with essential hypertension in different gender: a case-control study. Medicine. 2018;97(42):e12917. doi:10.1097/MD.00000000 00012917

38. Chen YY, Zhang P, Zhou XM, et al. Relationship between genetic variants of ACE2 gene and circulating levels of ACE2 and its metabolites. J Clin Pharm Ther. 2018;43(2):189-195. doi:10.1111/ jcpt. 12625

39. Burrell LM, Harrap SB, Velkoska E, Patel SK. The ACE2 gene: its potential as a functional candidate for cardiovascular disease. Clin Sci (Lond). 2013;124(2):65-76. doi:10.1042/CS20120269

40. He J, Lu Y-P, Li J, et al. Fetal but not maternal Angiotensin Converting Enzyme (ACE)-2 gene Rs2074192 polymorphism is associated with increased risk of being a Small For Gestational Age (SGA) newborn. Kidney Blood Press Res. 2018;43(5):1596-1606. doi:10.1159/000494449 
41. Pan Y, Wang T, Li Y, et al. Association of ACE2 polymorphisms with susceptibility to essential hypertension and dyslipidemia in Xinjiang, China. Lipids Health Dis. 2018;17(1):241. doi:10.1186/s12944-0180890-6

42. Lu N, Yang Y, Wang Y, et al. ACE2 gene polymorphism and essential hypertension: an updated meta-analysis involving 11,051 subjects. Mol Biol Rep. 2012;39(6):6581-6589. doi:10.1007/s11033-0121487-1

43. Fan X, Wang Y, Sun K, et al. Polymorphisms of ACE2 gene are associated with essential hypertension and antihypertensive effects of captopril in women. Clin Pharmacol Ther. 2007;82(2):187-196. doi:10.1038/sj.clpt.6100214

44. Chen YY, Liu D, Zhang P, et al. Impact of ACE2 gene polymorphism on antihypertensive efficacy of ACE inhibitors. J Hum Hypertens. 2016;30(12):766-771. doi:10.1038/jhh.2016.24

45. Vangjeli C, Dicker P, Tregouet D-A, Shields DC, Evans A, Stanton AV. A polymorphism in ACE2 is associated with a lower risk for fatal cardiovascular events in females: the MORGAM project. J Renin Angiotensin Aldosterone Syst. 2011;12(4):504-509. doi:10.1177/1470320311405557

46. Malard L, Kakinami L, O'Loughlin J, et al. The association between the angiotensin-converting enzyme-2 gene and blood pressure in a cohort study of adolescents. BMC Med Genet. 2013;14:117. doi:10.1186/1471-2350-14-117

47. Fan Z, Wu G, Yue M, et al. Hypertension and hypertensive left ventricular hypertrophy are associated with ACE2 genetic polymorphism. Life Sci. 2019;225:39-45. doi:10.1016/j.1fs.2019.03.059

48. Lieb W, Graf J, Gotz A, et al. Association of angiotensin-converting enzyme 2 (ACE2) gene polymorphisms with parameters of left ventricular hypertrophy in men. Results of the MONICA augsburg echocardiographic substudy. J Mol Med (Berl). 2006;84(1):88-96. doi:10.1007/s00109-005-0718-5

49. Wang S-X, Tao T, Fu Z-Q, Xie X-Z, Wang H, Wang Y-T. Polymorphisms of angiotensin-converting enzyme 2 gene confer a risk to lone atrial fibrillation in Chinese male patients. Chin Med $J$ (Engl). 2013;126(24):4608-4611.

50. Wu X, Zhu B, Zou S, Shi J. The association between ACE2 gene polymorphism and the stroke recurrence in Chinese population. J Stroke Cerebrovasc Dis. 2018;27(10):2770-2780. doi:10.1016/j. jstrokecerebrovasdis.2018.06.001

51. Liu D, Chen Y, Zhang P, et al. Association between circulating levels of ACE2-Ang-(1-7)-MAS axis and ACE2 gene polymorphisms in hypertensive patients. Medicine. 2016;95(24):e3876. doi:10.1097/ MD.0000000000003876

52. Adamzik M, Frey U, Sixt S, et al. ACE I/D but not AGT (-6)A/G polymorphism is a risk factor for mortality in ARDS. Eur Respir J. 2007;29(3):482-488. doi:10.1183/09031936.00046106

53. Saab YB, Gard PR, Overall ADJ. The geographic distribution of the ACE II genotype: a novel finding. Genet Res. 2007;89(4):259-267. doi:10.1017/S0016672307009019

54. Chiu RWK, Tang NLS, Hui DSC, et al. ACE2 gene polymorphisms do not affect outcome of severe acute respiratory syndrome. Clin Chem. 2004;50(9):1683-1686. doi:10.1373/clinchem.2004.035436

55. Goulter AB, Goddard MJ, Allen JC, Clark KL. ACE2 gene expression is up-regulated in the human failing heart. BMC Med. 2004;2 (1):19. doi:10.1186/1741-7015-2-19

56. Delanghe JR, Speeckaert MM, De Buyzere ML. The host's angiotensin-converting enzyme polymorphism may explain epidemiological findings in COVID-19 infections. Clin Chim Acta 2020;505:192-193. doi:10.1016/j.cca.2020.03.031

57. Imai Y, Kuba K, Ohto-Nakanishi T, Penninger JM. Angiotensinconverting enzyme 2 (ACE2) in disease pathogenesis. Circ J. 2010;74(3):405-410. doi:10.1253/circj.cj-10-0045

58. Stawiski EW, Diwanji D, Suryamohan K, et al. Human ACE2 receptor polymorphisms predict SARS-CoV-2 susceptibility. bioRxiv. 2020;2020.04.07.024752. doi:10.1101/2020.04.07.024752
59. Cao Y, Li L, Feng Z, et al. Comparative genetic analysis of the novel coronavirus (2019-nCoV/SARS-CoV-2) receptor ACE2 in different populations. Cell Discov. 2020;6(1):4-7. doi:10.1038/s41421-0200147-1

60. Wu JT, Leung K, Bushman M, et al. Estimating clinical severity of COVID-19 from the transmission dynamics in Wuhan, China. Nat Med. 2020;26(4):506-510. doi:10.1038/s41591-020-0822-7

61. Vickers C, Hales P, Kaushik V, et al. Hydrolysis of biological peptides by human angiotensin-converting enzyme-related carboxypeptidase. J Biol Chem. 2002;277(17):14838-14843. doi:10.1074/jbc.M2005 81200

62. Serfozo P, Wysocki J, Gulua G, et al. Ang II (angiotensin II) conversion to angiotensin-(1-7) in the circulation is POP (prolyloligopeptidase)-dependent and ACE2 (Angiotensin-Conve rting Enzyme 2)-independent. Hypertens. 2020;75(1):173-182. doi:10.1161/HYPERTENSIONAHA.119.14071

63. Fang L, Karakiulakis G, Roth M. Are patients with hypertension and diabetes mellitus at increased risk for COVID-19 infection? Lancet Respir Med. 2020;8(4):e21. doi:10.1016/S2213-2600(20)30116-8

64. Zhang P, Zhu L, Cai J, et al. Association of inpatient use of angiotensin converting enzyme inhibitors and angiotensin II receptor blockers with mortality among patients with hypertension hospitalized with COVID-19. Circ Res. 2020. doi:10.1161/CIRCRESAHA. 120.317134

65. Li XC, Zhang J, Zhuo JL. The vasoprotective axes of the renin-angiotensin system: physiological relevance and therapeutic implications in cardiovascular, hypertensive and kidney diseases. Pharmacol Res. 2017;125(Pt A):21-38. doi:10.1016/j.phrs.2017. 06.005

66. Caldeira D, Alarcao J, Vaz-Carneiro A, Costa J. Risk of pneumonia associated with use of angiotensin converting enzyme inhibitors and angiotensin receptor blockers: systematic review and meta-analysis. BMJ. 2012;345(jul11 1):e4260. doi:10.1136/bmj.e4260

67. Wirtz H, Hasenclever D, Schwabe K, et al. ACE inhibitor for lung protection during mechanical ventilation for acute lung injury results of the double-blind, placebo controlled, randomised ACEmeVENT pilot study. In: B16. Critical Care: New Insights From Clinical Trials. American Thoracic Society International Conference Abstracts. American Thoracic Society; 2017:A2895A2895. doi:10.1164/ajrccm-conference.2017.195.1_MeetingAbstr acts.A2895

68. Kim J, Choi SM, Lee J, et al. Effect of renin-angiotensin system blockage in patients with acute respiratory distress syndrome: a retrospective case control study. Korean J Crit Care Med. 2017;32(2):154-163. doi:10.4266/kjccm.2016.00976

69. Sun ML, Yang JM, Sun YP, Su GH. Inhibitors of RAS might be a good choice for the therapy of COVID-19 pneumonia. Zhonghua Jie He He Hu Xi Za Zhi. 2020;43:E014. doi:10.3760/cma.j.issn.10010939.2020.0014

70. Peng YD, Meng K, Guan HQ, et al. Clinical characteristics and outcomes of 112 cardiovascular disease patients infected by 2019-nCoV. Zhonghua Xin Xue Guan Bing Za Zhi. 2020;48:E004. doi:10.3760/cma.j.cn112148-20200220-00105

71. Danser AHJ, Batenburg WW, van den Meiracker AH, Danilov SM. ACE phenotyping as a first step toward personalized medicine for ACE inhibitors. Why does ACE genotyping not predict the therapeutic efficacy of ACE inhibition? Pharmacol Ther. 2007;113 (3):607-618. doi:10.1016/j.pharmthera.2006.12.001

72. Sommerstein R, Kochen MM, Messerli FH, Gräni C. Coronavirus disease 2019 (COVID-19): do angiotensin-converting enzyme inhibitors/angiotensin receptor blockers have a biphasic effect? $\mathrm{J} \mathrm{Am}$ Heart Assoc. 2020;9(7):e016509. doi:10.1161/JAHA.120.016509

73. Liu Z, Xiao X, Wei X, et al. Composition and divergence of coronavirus spike proteins and host ACE2 receptors predict potential intermediate hosts of SARS-CoV-2. J Med Virol. 2020;92(6):595-601. doi:10.1002/jmv.25726 
74. Mancia G, Rea F, Ph D, et al. Renin-angiotensin-aldosterone system blockers and the risk of Covid-19. N Engl J Med. 2020:1-10. doi:10.1056/NEJMoa2006923

75. Mehra MR, Desai SS, Kuy S, Henry TD, Patel AN. Cardiovascular disease, drug therapy, and mortality in Covid-19. $N$ Engl J Med. 2020;1-8. doi:10.1056/NEJMoa2007621

76. Reynolds HR, Adhikari S, Pulgarin C, et al. Renin-angiotensinaldosterone system inhibitors and risk of Covid-19. $N$ Engl J Med. 2020:1-8. doi:10.1056/NEJMoa2008975

77. de Simone G. Position Statement of the ESC Council on Hypertension on ACE-Inhibitors and Angiotensin Receptor Blockers. European Society of Cardiology.13.03.2020
78. Bozkurt B, Kovacs R, Harrington B. HFSA/ACC/AHA Statement Addresses Concerns Re: Using RAAS Antagonists in COVID-19. American College of Cardiology. 17.03.2020

79. U.S. National Library of Medicine. 2020. Available from: ClinicalTrials. Gov. ClinicalTrials.gov. https://clinicaltrials.gov. Accessed June 7, 2020.

80. University Hospital Strasbourg France. Efficacy of hydroxychloroquine, telmisartan and azithromycin on the survival of hospitalized elderly patients with COVID-19 (COVID-aging). 2020. Available from: ClinicalTrials.gov. https://clinicaltrials.gov/ct2/show/ NCT04359953 term $=$ arb\& cond $=$ covid $-19 \&$ draw $=5 \&$ rank $=36$. Accessed June 7, 2020.

\section{Publish your work in this journal}

Clinical Interventions in Aging is an international, peer-reviewed journal focusing on evidence-based reports on the value or lack thereof of treatments intended to prevent or delay the onset of maladaptive correlates of aging in human beings. This journal is indexed on PubMed Central, MedLine, CAS, Scopus and the Elsevier
Bibliographic databases. The manuscript management system is completely online and includes a very quick and fair peer-review system, which is all easy to use. Visit http://www.dovepress.com testimonials.php to read real quotes from published authors. 